\title{
EFFECTIVE SHEAR VISCOSITY AND EFFECTIVE BULK VISCOSITY OF FIRN OF A TEMPERATE GLACIER (KESSELWANDFERNER, ÖTZTAL ALPS, 1967-1978)
}

\author{
by \\ Walter Ambach \\ (Institut für Medizinische Physik der Universität Innsbruck, Müllerstrasse 44, A-6020 Innsbruck, \\ Austria) \\ and Heinrich Eisner \\ (Institut für Experimentalphysik der Universität Innsbruck, Innrain 100, A-6020, Innsbruck, Austria)
}

\begin{abstract}
Strain-rate measurements were carried out over eleven years on a firn pit $20 \mathrm{~m}$ deep in a temperate glacier. The stress strain-rate relation was applied in terms of invariants, because of the multiaxial state of stresses. The shear viscosity and the bulk viscosity were calculated as a function of depth and density. The result must be understood in terms of effective viscosities as the dependence of the viscosity from the state of stresses is unknown in this analysis.
\end{abstract}

\section{INTRODUCTION}

Strain-rate measurements on a firn pit $20 \mathrm{~m}$ deep were made to gain a better insight on the movement of the firn of a temperate glacier. The firn pit originally had a depth of $20 \mathrm{~m}$, a dianeter of $2 \mathrm{~m}$ and an approximately circular cross-section. At 14 levels of different depths 6 or 7 gauges on each level were set in the pit walls, which were measured once a year in JuTy between 1967 and 1978. Yearly-averaged strainrates are obtained, no seasonal variations being taken into account. Greater details on the measurement and analysis of the strain-rates are given in Eisner and Ambach (1981).

The stratigraphy and the density profile at the site of the measurements were taken from studies on an analogous firn pit in the immediate neighbourhood (Ambach and Eisner 1966). The firn pit lies in the central region of the accumulation area, the slope of the surface being approximately $5^{\circ}$. The averaged water equivalent of the annual net accumulation for the period from 1967 to 1980 amounts to $1.3 \mathrm{~m}$. The transition zone of firn into glacier ice lies approximately 25 to $28 \mathrm{~m}$ deep (Behrens and others 1979). Mel twater percolation through the firn occurs during midsummer in warm periods. The site of the measurements cannot be claimed as a neutral zone in relation to the state of stress.

It is the aim of the present paper to give new information on the rheological properties of the firn of a temperate glacier from strain-rate measurements on a firn pit. Field experiments of this kind are better than laboratory experiments as the firn and ice structure and the stress correspond to conditions in nature.

\section{STRAIN-RATES}

The following deformation effects have become evident (Eisner and Ambach 1981).

(a). The creep profile obtained by the measured shear strain can be approximated by a straight line. The velocity gradient is thus approximately constant and independent of the depth. From the linear creep profile and the shear stress the effective shear viscosity can be calculated as a function of depth. (b). The deformation of an approximately circular cross-section into an elliptical one is inarked by the hexagonally arranged gauges. Changes of the measured strain-rates with time cannot be confirmed clearly, and no statements on the effects of secondary and tertiary creep can be made.

(c). Progressive immersion of the levels into the firn takes place, due to the vertical component of movement, which is generated by both the settlement of the snow by compression and the thinning of the snow layers by the tensile stress occurring in the accumulation area of glaciers. This tensile stress is related to the increase of the velocity in the direction of the flow.

All strain-rates were calculated as averaged strain-rates over the period of measurements. Therefore, no time dependence of the strain-rates can be taken into account. The linear creep profile in the firn of a temperate glacier shows a shear deformation similar to that of the well-settled snow pack (McClung 1980) and differs significantly from parabolic creep profiles obtained in incompressible glacier ice (Savage and Paterson 1963).

\section{EFFECTIVE SHEAR VISCOSITY AND EFFECTIVE BIJLK} VISCOSITY

For determining the shear viscosity and the bulk viscosity of firn, a stress strain-rate relation must be derived. As the firn is a compressible medium having a multi-axial state of stress with superimposed shear stress, the problem can be solved in terms of invariants. Great efforts have been made to 
create a constitutive equation describing the rheological behaviour of snow in general (Salm 1982). However, for practical application, a simplified model is needed to reflect the predominant properties of the firn.

\subsection{Constitutive equation}

The stress tensor and the strain-rate tensor can be written in the form

$$
\sigma_{i j}=\sigma_{i j}+\frac{I_{1}}{3} \delta_{i j} \text {, }
$$

and

$$
\dot{e}_{i j}=\dot{e}_{i j}+\frac{J_{1}}{3} \delta_{i j},
$$

where $\sigma_{i j}, \dot{e}_{i j}$ are the components, $\sigma_{i j}, \dot{e}_{i j}$ are the deviators, $I_{1}, J_{1}$ are the first invariants and $\delta_{i j}$ is the Kronecker symbol. The shear viscosity $\mu$ and the bulk viscosity $n$ are introduced by definition as follows:

$$
\sigma_{i j}=2 \mu \dot{e}_{i j},
$$

and

$$
I_{1}=3 n \mathrm{~J}_{1} \text {. }
$$

Therefore it holds that

$$
\begin{aligned}
& \sigma_{i j}=2 \mu \dot{e}_{i j}+\frac{I_{1}}{3} \delta_{i j} \\
& \sigma_{i j}=2 \mu\left(\dot{e}_{i j}-\frac{J_{1}}{3} \delta_{i j}\right)+\eta J_{1} \delta_{i j},
\end{aligned}
$$

and

$$
\sigma_{i j}=2 \mu \dot{\mathrm{e}}_{i j}+\left(n-\frac{2}{3}\right) \mathrm{J}_{1} \delta_{i j} .
$$

Introducing the parameter $k$ by

$$
k=(3 \eta-2 \mu) \frac{J_{1}}{I_{1}}
$$

the constitutive Equation (7) can be rewritten

$$
\sigma_{i j}=2 \mu \dot{e}_{i j}+k \frac{I_{1}}{3} \delta_{i j}
$$

and the ratio $n / \mu$ becomes by comparison of Equations (8) and (4)

$$
\frac{I_{1}}{J_{1}}=\frac{3 n-2 \mu}{k},
$$

$$
\begin{aligned}
& \frac{I_{1}}{J_{1}}=3 \eta, \\
& \frac{n}{\mu}=\frac{2}{3} \cdot \frac{1}{1-k} .
\end{aligned}
$$

The parameter $k$ is a quantity depending mainly on the compressibility of the firn, with $k=1$, when the material is noncompressible. $k$ is related to the viscose analogical forin of the Poisson's elastic ratio $v$, which is defined for an uniaxial state of stress by

$$
\frac{-\dot{\mathrm{e}}_{22}}{\dot{\mathrm{e}}_{11}}=\frac{-\dot{\mathrm{e}}_{33}}{\dot{\mathrm{e}}_{11}}=v \text {. }
$$

From Equation (9) it holds with $\sigma_{11}=\mathrm{I}_{1}$

$$
\frac{-\dot{e}_{22}}{\dot{e}_{11}}=\frac{k}{3-k}
$$

and by comparison of Equations (11) and (12) results in

$$
k=\frac{3 v}{v+1} \quad .
$$

The quantity $k$, the shear viscosity $\mu$ and the bulk viscosity $n$ depend on density and on other structural parameters and/or on stress invariants (Salm 1977). As the dependence of the shear and bulk viscosity from the state of stress is unknown in this experiment, numerical values are introduced as effective viscosities which are only valid for the state of stress under investigation. The idea behind this approach is that the field experiment indicates natural conditions which are difficult to reproduce in laboratory tests. 3.2. Results

The following quantities are known from the field experiment: the strain-rates $\dot{e}_{11}$, $\dot{e}_{22}, \dot{e}_{33}$, $\dot{e}_{12}$ and the stresses $\sigma_{22}, \sigma_{12}$. Index 1 denotes the direction of the flow, 2 the direction of depth, and 3 the direction transverse to the flow.

The evaluation was made by the following steps: (a). Calculation of the shear viscosity $\mu$ as a function of depth, obtained from the creep profile and the shear stress (Table I) by

$$
\mu=\frac{1}{2} \frac{\sigma_{12}}{\dot{e}_{12}},
$$

with

TABLE I. SHEAR STRAIN-RATE $\dot{e}_{12}$, SHEAR STRESS $\sigma_{12}$, AXIAL SNOW LOAD $\sigma_{22}$, EFFECTIVE SHEAR VISCOSITY $\mu$ AND EFFECTIVE BULK VISCOSITY $n$ OF FIRN IN DEPENDENCE OF DEPTH, DENSITY AND CROSS-SECTION NUMBER

$\begin{array}{ccccccccc}\text { Layer } & \begin{array}{c}\text { Depth } \\ \text { (m) }\end{array} & \begin{array}{c}\text { Density } \\ \left(\mathrm{kg} \mathrm{m}^{-3}\right)\end{array} & \begin{array}{c}\text { Cross-section } \\ \text { number }\end{array} & \begin{array}{c}\dot{\mathrm{e}}_{12} \\ \left(\times 10^{-1} \mathrm{~s}^{-1}\right)\end{array} & \begin{array}{c}\sigma_{12} \\ \left(\times 10^{3} \mathrm{~Pa}\right)\end{array} & \sigma_{22} & \mu & \eta \\ & & & & & & & \\ 1-2 & 24.0 & 862.5 & 2.31 & -5.23 & -16.65 & -185 & 1.59 & 1.14 \\ 2-3 & 22.9 & 858.5 & 2.33 & -5.23 & -15.93 & -177 & 1.52 & 1.01 \\ 3-4 & 22.2 & 855.5 & 2.35 & -5.23 & -15.30 & -170 & 1.46 & 0.92 \\ 4-5 & 21.2 & 850.5 & 2.39 & -5.23 & -14.58 & -162 & 1.40 & 0.82 \\ 5-6 & 20.2 & 846.5 & 2.41 & -5.23 & -13.95 & -155 & 1.33 & 0.73 \\ 6-7 & 19.1 & 840.5 & 2.45 & -5.23 & -13.05 & -145 & 1.25 & 0.63 \\ 7-8 & 17.5 & 830.0 & 2.52 & -5.23 & -11.79 & -131 & 1.13 & 0.50 \\ 8-9 & 16.1 & 820.5 & 2.59 & -5.23 & -10.89 & -121 & 1.04 & 0.42 \\ 9-10 & 14.3 & 805.0 & 2.69 & -5.23 & -9.63 & -107 & 0.92 & 0.33 \\ 10-11 & 11.6 & 770.0 & 2.94 & -5.23 & -7.74 & -87 & 0.74 & 0.21\end{array}$




$$
\sigma_{12}=\int_{0}^{y_{0}} \rho g \sin \alpha \cdot d y
$$

and

$$
\dot{e}_{12}=\frac{1}{2}\left(\frac{\partial v_{y}}{\partial x}+\frac{\partial v_{x}}{\partial y}\right),
$$

where $\rho$ is the density, $g$ the gravity, $\alpha$ the slope and $v_{x}, v_{y}$ are the components of the velocity in the direction of the flow and the direction of the depth. It follows from velocity measurements on the glacier surface that the term $\partial v_{y} / \partial x$ can be neglected (Schneider unpublished).

(b). Calculation of the quantity $k$ as a function of depth from Equation (13). The ratio $v$, being by definition reciprocal to the cross-section number, is given as a function of density by Bader and others (1951). Any dependence of $k$ from the state of stresses is neglected, as the state of stresses is unknown.

(c). Calculation of the bulk viscosity $n$ as a function of depth by

$$
n=\frac{2}{3} \mu \frac{1}{1-k} \text {, }
$$

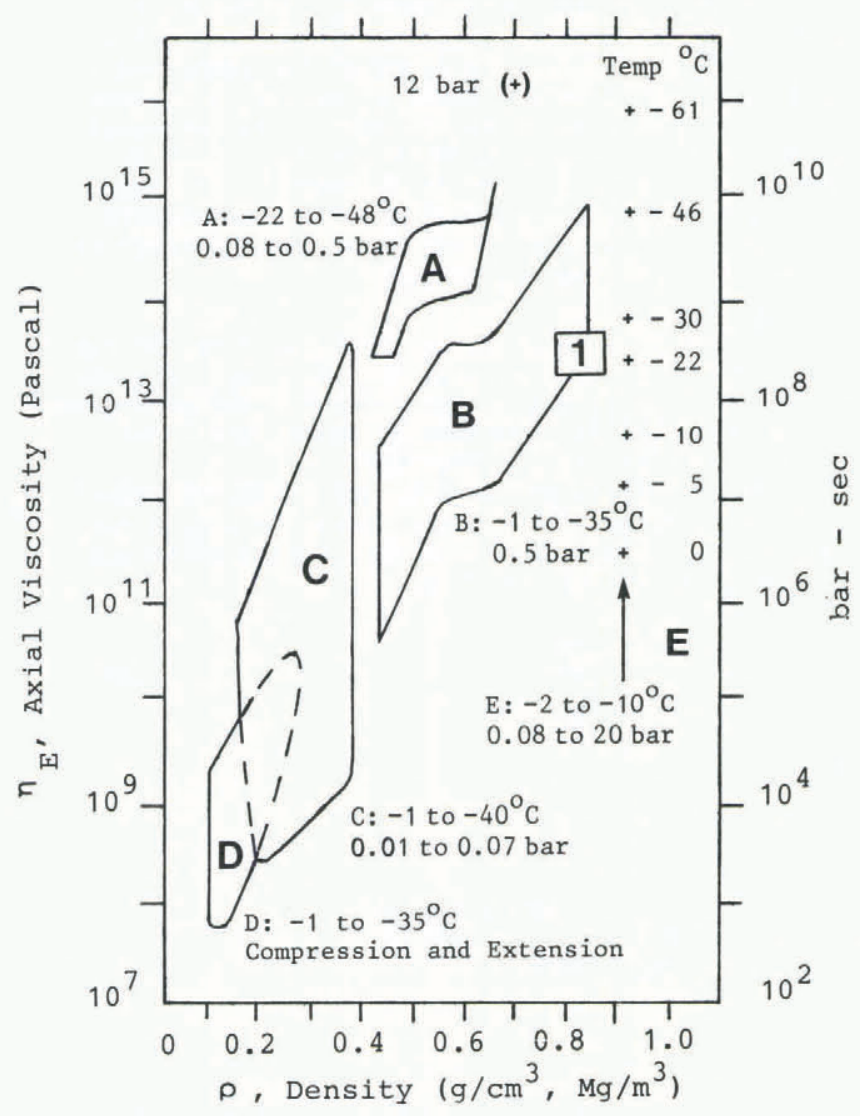

Fig.1. Axial viscosity of firn of a temperate glacier (1) calculated from the effective shear and effective bulk viscosities of the present paper by $n_{E}=9\left(\mu_{e f f} \cdot n_{\text {eff }}\right) /\left(3 n_{\text {eff }}+\mu_{\text {eff }}\right)$ (Mellor 1975). Comparison of axial viscosities of different snow types (A to E) after Mellor (1975). Data of the present analysis (1) are temperature: summer $0^{\circ} \mathrm{C}$, winter $-10^{\circ} \mathrm{C}$ (estimated); stresses: shear stress -7.74 to $-16.65 \times 10^{3} \mathrm{~Pa}$; vertical axial snow load -87 to $-185 \times 10^{3} \mathrm{~Pa}$; Heff and $n_{\text {eff }}$ see Table I. using the shear viscosity $\mu$ and the quantity $k$ as a function of depth (Table I).

Both the effective shear viscosity and the effective bulk viscosity increase with depth, partly due to increasing density and incompressibility and partly due to increasing normal stress in agreement with results obtained for a well-settled snowpack (McClung unpublished). The results fit very well into a graph showing the viscosity as a function of density for different types of snow (Fig.1).

In the present analysis, it is a hypothesis that snow is an isotropic medium and that the stress deviator tensor is linearly proportional to the strain-rate deviator tensor, the constant of proportionality being independent of speed and memory effect.

\section{CONCLUSIONS}

The following critical considerations must be taken into account. Firstly, the shear viscosity $\mu$ and the bulk viscosity $n$ depend strongly on temperature, structure and state of stresses. The numerical result must therefore be understood in terms of effective shear viscosity and effective bulk viscosity. It is not possible to determine the viscosity function as introduced by Salm (1967). Secondly, the firn is an anisotropic material because of its horizontal stratification. However, the equations used in this paper are those for an isotropic material. Therefore the effective shear viscosity determined from the shear stresses may differ from that determined from axial stresses. Thirdly, the calculated effective viscosities are mean values valid for each individual level. It must be considered that significant changes in depth, density and stresses occur for each level during the period of measurements. However, the influence of temperature is of less importance, as the firn pit was dug in a temperate glacier.

\section{ACKNOWLEDGEMENTS}

The project was assisted with the financial support of the Osterreichische Akademie der Wissenschaften, Vienna. Transport was supplied by the Bundesministerium für Inneres, Vienna. The authors express their thanks to Dr H Jessberger, Dr D McClung, Dr C Raymond and Dr B Salm for making comments on the problem and to Mr K Kimeswenger for cooperating in the evaluation. The more detailed manuscript will be submitted to Zeitschrift für Gletscherkunde und Glazialgeologie.

\section{REFERENCES}

Ambach W, Eisner H 1966 Analysis of a $20 \mathrm{~m}$ firn pit on the Kesselwandferner (Otztal Alps). Jourmal of Glaciology 6(44): 223-231

Bader H, Hansen B L, Joseph J H, Sandgren M A 1951 Preliminary investigations of some physical properties of snow. SIPRE Report 7

Behrens $\mathrm{H}$ and 7 others 1979 Neue Ergebnisse zur Bewegung des Schmelzwassers in Firnkorper des Akkumulationsgebietes eines Alpengletschers (Kesselwandferner-0tztaler Alpen). Zeitschrift für Gletscherkunde und Glazialgeologie 15(2): 219-228

Eisner H, Ambach W 1981 Strain rate measurements on a $20 \mathrm{~m}$ deep firn pit in a temperate glacier (Kesselwandferner, Otztal Alps 1967-1978). Zeitschrift flir Gletscherkunde und Glazialgeologie 17(1): 169-176

McClung D M 1980 Creep and glide processes in mountain snow packs. Ottawa, Inland Waters Directorate. National Hydrology Research Institute (NHRI Paper 6)

McClung D M Unpublished. Avalanche defense mechanics. ( $\mathrm{PhD}$ thesis, University of Washington, 1974)

Mellor M 1975 A review of basic snow mechanics. Intermational A6sociation of Hydrological Sciences Publication 114 (Symposium of Grindelwald 1974 Snow Mechanics): 251-291 
Salm B 1967 An attempt to clarify triaxial creep mechanics of snow. In Oura $\mathrm{H}$ (ed) Physics of snow and ice. Intermational conference on low temperature science...1966 Sapporo. Proceedings Vol 1 , Part 2. Hokkaido, Hokkaido University. Institute of Low Temperature Science: 857-874

Salm B 1977 Snow forces. Joumal of Glaciology 19(81): $67-100$

Salm B 1982 Mechanical properties of snow. Reviews of Geophysics and Space Physics 20(1): 1-19

Savage J C, Paterson W S B 1963 Borehole measurements in the Athabasca Glacier. Jourmal of Geophysical Research 68(15): 4521-4536

Schneider $H$ Unpublished. Die Grund]agen der Vermessungen am Kesselwandferner (0tztaler Alpen) und die Bewegung dieses Gletschers in den Haushaltsjahren 1965/67 und 1967/68. (PhD thesis, Universitat Innsbruck, 1970) 